que essa pesquisa deveria ser feita com algum interesse, porque nenhum conhecimento deverá ser considerado como superfluo, em uma molestia tão espalhada entre nós e que tantos prejuizos nos causa.

\title{
Toxicodernias consecutivas ao tratamento da syphilis
}

\author{
Pelo quarto innista Romeu da Silveire
}

Todos os medicamentos actualmente utilisados no trata. mento da syphilis, provêm, em sua quasi que totalidade, de tres corpos ehimicos, os quaes, como muito bem se sabe, sã o iodo, o mercurio e o arsenico. E' sobre a acção toxica que qualquer um delles possa exercer sobre a pelle, que pretendemos fazer este ligeiro e despretencioso estudo o qual, affirmamos desde já, será por certo bastante incompleto. Esta questão de toxicodermias tem sido despresada por quasi todos e muitas vezes, para não dizer quasi sempre, pensa-se que certas erupções toxicas da pelle, em individuos submettidos á therapeutica anti-luetica, sejam apenas lesões syphiliticas; e é bem triste constatar-se, como já tivemos occasião, o facto de terem sido receitadas as pilulas de Ricord a um individuo que apresentava $A C N E$ IODICA typica na fronte, como si tal exanthema fôra syphilitico.

\section{$I O D O$}

O iodo, descoberto em 1811 por BERNARDO COURTOIS, foi por WALLACE de Dublin, preconisado pela primeira vez no tratamento da syphilis, sob a fórma de iodeto de potassio, tratamento esse que, graças ao grande RICORD, foi largamente vulgarisado em França sobretudo contra a syphilis terciaria, da qual é elle hoje o especifico. Porém, sobre ser medicamento anti-luetico, póde, o metalloide de COURTOIS, actuar tambem sobre o organismo, produzindo não raramente graves envenenamentos. 
Antes de examinar os accidentes de intoxicação iodica da pelle, não é descabido dirigir a attenção rapidamente sobre alguns symptomas de uma intoxicação geral. Um facto interessante a relembrar é que os phenomenos de intoxicação sejam elles graves ou benignos não se acham nunca em relação á dose do medicamento; nem tão pouco esses accidentes referem-se ao poder toxico especifico dos compostos iodicos, mas sim, como diz POUCHET, á intolerancia que certos organismos têm para com taes compostos.

Em seguida a uma forte irritação da mucosa digestiva causada pelos iodetos, podem-se revelar como symptomas typicos sabôr metallico da saliva, anorexia e diarrhéa. Si o medicamento é administrado "per os" podemos verificar uma violenta irritação da mucosa gastrica dando origem a phenomenos dyspepticos e mais raramente a nauseas, vomitos repetidos algumas vezes sanguinolentos e dôres epigastricas intensas.

Certas perturbações secretorias são tambem manifestas: taes são coryzas agudos produzidos pela hyper-secreção da mucosa pituitaria; inflammações da mucosa laryngo-bronchica; a turgescencia e a hyper-secreção da mucosa ocular se nos traduzem por um lacrimejar continuo. Podemos tambem apreciar affecções renaes e lesões cardiacas, julgando hoje os auctores serem estes factos devidos a um accumulo de iodo por insufficiente eliminação. Entre os accidentes mais graves que a litteratura nos cita, temos o edema da glotte e a hemorrhagia cerebral. O systema nervoso tambem mostra-nos disturbios sensitivos e sensoriaes, delirio, etc., cujo conjuncto constitue a chamada EMBRIAGUEZ IODICA, accidente aliás muito raro. A cephaléa quasi sempre acompanha estes phenomenos. Acreditam alguns auctores que os iodetos possam provocar hemoptyse nos tuberculosos. Querem tambem que os iodetos possam determinar a molestia de BASEDOW talvez por influirem sobre a secreção da thyroide.

Passemos agora a falar. sobre a questão a que nos propuzemos, isto é, sobre as intoxicações cutaneas.

$A C N E$ IODICA - E' esta a fórma por que mais frequentemente se apresenta a intoxicação iodica. Formam-se sobre a pelle, pustulas mais ou menos desenvolvidas, que mui- 
to se assemelham ás da $A C N E$ VULGAR E ACNE BROMI$C A$; a base é fortemente infiltrada e circumdada por uma zona hyperhemica muito maior que a da acne vulgar mas menor que a da acne bromica. As pustulas são muito numerosas e mais ou menos grandes e são encontradas em geral nos pontos predilectos de todas as acnes: no rosto, sobre a fronte e visinhanças do nariz; no peito e no dorso; ellas se podem mostrar em outras regiões do corpo assim como podem tambem se generalisar. Em certos casos as pustulas acneicas podem confluir, tomando então o aspecto de uma pustula maligna (aspecto anthracoide).

$O$ diagnostico differencial com a ACNE VULGAR fazse, tomando em consideração o facto de que na ACNE IODI$C A$ ha o desenvolvimento agudo de muitas pustulas contemporaneamente; a acne vulgar principia em geral no estado de cravos dos folliculos sebaceos passando depois ao estado de papulas inflammatorias para chegar ao pustuloso; na acne iodica não ha essa serie evolutiva. A anamnese e a presença de iodo nas urinas tambem são factores importantes de diagnostico differencial. Ha uma fórma de syphilis que se manifesta por um exanthema papulo-pustuloso acneiforme mas distingue-se facilmente das outrás acnes pelos caracteres inflammatorios e dolorosos destas.

PURPURA IODICA - Eis aqui outro accidente da intoxicação iodica produzido por hemorrhagias cutaneas e subcutaneas grandes ou pequenas e geralmente sobre os membros inferiores. Como todas as purpuras da pelle caracterisase pelo facto dé que sob a pressão não perde a côr que varia entre vermelho claro e violeta. $O$ diagnostico differencial entre a purpura iodica e a peliosis rheumatica de Schönlein, que apresenta as mesms efflorescencias e as mesmas sédes, fazse pelo estado geral porque na peliosis rheumatica temos dôres articulares principalmente nos joelhos, augmento febril de temperatura, e, outras hemorrhagias podem apparecer nos braços e nas coxas emquanto as primeiras vão desapparecendo com as modificações chromaticas de todas as hemorrhagias da pelle. O morbus maculosus de Werlhof além de ser affecção mais grave, distingue-se da purpura iodica porqü as hemorrhagias apparecem em toda a pelle e sem disposição 
determinada, attingindo tambem o revestimento mucoso dos orgãos internos.

PEMPHYGO IODICO - A's vezes, em seguida ao uso de iodetos, observamos um exanthema bolhoso pemphygoide que póde ser. confundido com os pemphygos. São bolhas de varios tamanhos contendo um liquido claro e hyalino. Este pemphygo iodico differencia-se do pemphygo agudo e dos chronicos pelo estado geral do doente. E' preciso não confundil-o tambem com outras manifestações pemphygoides como 0 p. neonatorum que, como diz LESSER, nada mais é senão o impetigo contagiosa; o pemphygo leproso, p. syphilitico, $p$. da scabies, e os pemphygos devidos a substancias irritantes como as cantharidas etc. Uma manifestação vesiculosa, verdadeiro HERPES IODICO tivemos. occasião de observar sobre a glande de um individuo em seguiḍa á applicação de iodoformio. Não se tratava aqui de um HERPES SIMPLES por irritação mecanica pois as vesiculas só recidivavam com a applicação de iodoformio.

IODODERMA TUBEROSO - Muitas vezes nós vemos um accidente grave devido á proliferação semelhante aos tumores das mycoses (esporothricose, actinomycose, etc.) Formam-se verdadeiros tuberculos sobre a pelle, de côr que póde variar desde vermelho pallido até vermelho azulado ou violaceo; de dimenșões varias e de consistencia dura. E' bom não confundir o iododerma tuberoso com as mycoses e as gommas no estado eruptivo. A's vezes em lugar de tubérculos podemos ter apenas nodulos erythematosos que se não devem confundir com o erythema nodoso. Esses nodulos ainda se podem reduzir a simples manchas erythematosas.

\section{MERCURIO}

Desde a mais longinqua antiguidade que é o mercurio utilisado no tratamento da syphilis, pois os chinezes ha mais de dois mil annos empregavam-no para tal fim. Hoje devemos considerar o mercurio como o medicamento anti-syphilitico por excellencia, porque elle cura de facto os accidentes actuaes da syphilis. Entretanto a medicação hydrargyrica tem os seus inconvenientes que, embora sejam faceis de se evi- 
tar, não deixam de ser inconvenientes; assim é que uma intoxicação chronica do organismo pode ser fatal si se não cortar o mal pela raiz supprimindo-se ou diminuindo as doses medicamentosas.

Diremos alguma cousa sobre a intoxicação geral do organismo antes de falarmos das toxicodermias mercuriaes. A estomatite mercurial, primeiro symptoma do hydrargyrismo pode provocar rapidamente a quéda dos dentes, ou revestir fórmas graves como a gangrena da bocca e o edema da glotte. Outros symptomas: salivação abundante de sabôr metallico, anorexia, dyspepsia, e diarrhéa consecutiva a uma enterite; edema com ou sem albuminuria dependendo isto de uma nephrite mercurial; depois anemia, emagrecimento e diar-1 rhéas persistentes. Este estado de cachexia profunda vae ao marasmo e depois á morte. O tremor mercurial manifesta-se ligeiramente a principio nos labios, nas mãos, na lingua, com pequenas amplitudes que augmentam só com fadigas, emoções ou excessos alcoolicos. Depois o tremor generalisa-se e accentua-se impedindo a coordenação de um só movimento.

$\mathrm{Na}$ pelle as fricções mercuriaes podem produzir uma dermatite ou ECZEMA ARTIFICIAL o qual é devido á acção irritante do mercurio sobre os estratos epidermicos. Este ECZEMA MERCURIAL é identico a todos os eczemas artificiaes produzidos por substancias chimicas; consequentemen. te o diagnostico é facil pela anamnése.

FOLLICULITE MERCURIAL - O mercurio pode penetrar nos folliculos dos pellos e dar origem, pela sua acção irritante, a uma inflammação desses folliculos e dos tecidos perifolliculares determinando um suppuração. Temos então pequenos nodulos isolados ou confluentes, pustulas, lesões estas perfuradas por pellos e quasi sempre recobertas por crostas. O processo inflammatorio é identico ao da FOLLICULITE ESTAPHYLLOGENA, affecção esta mais commum que a mercurial.

ERYTHEMA MERCURIAL - Esta affecção pode algumas vezes ser confundida com a escarlatina. Este exanthema erythematoso é observado ou depois de injecções mercuriaes ou mais frequentemente depois de fricções com unguentos mercuriaes. O erythema mercurial manifesta-se por mui- 
tos pontos e manchas roseas ou avermelhadas, tendendo a se confluir e reunir. Este exanthema pode generalisar-se em certas zonas ou em todo o corpo, e o erytherha pode nestas condições tormar-se vermelho mais carregado donde a sua confusão com a escarlatina.

Exanthema analogo a este erythema hydrargyrico, tivemos ensejo de observar, em seguida a uma injecção endo-venosa de tartaro emetico, em um doente de leishmaniose da clinica dermatologica da nossa Faculdade. Este erythema tartarico é muito raro e cremos mesmo não ter sido ainda descripto pelos auctores.

\section{ARSENICO}

$\mathrm{O}$ arsenico foi empregado ha já bastante tempo no tratamento da syphilis ; $B R O C Q$ ajuntava á àção do mercurio, o cacodylato de sódio. O atoxil descoberto por BE'CHAMP em 1836 foi muito aconselhado nesse tratamento. p̣ahi até os nossos dias o arsenico passou a ser objecto de accurados estudos em syphiligraphia até as grandes descobertas de $E H R L I C H$ que nos vieram trazer novas luzes e dar outra orientação á therapeutica da syphilis. Infelizmente é o arsenico, de todos os medicamentos anti-lueticos, o mais perigoso porque é elle que dentre todos, dá origem a mais casos de intoxicação e a intoxicações mais graves. Vamos examinar muito rapidamente e não entraremos em particularidade alguma no assumpto que se refere á intoxicação geral pelo arsenico porque é uma questão muito vasta e não nos interessa no momento.

Devemos mencionar sómente o seguinte: vomitos numerosos, diarrhéa ás vezes sanguinolenta, catarrho laryngobronchico, aphoniá, coryza intenso, lacrimejar, cephaléa; dôres intensas articulares, diminuição da sensibilidade podendo mesmo desapparecer totalmente, e podemos ter emfim phenomenos de paralysia.

As manifestações cutaneas que o arsenico póde produzir são rarissimas no tratamento da syphilis. Dos accidentes que vamos descrever, julgamos mesmo que alguns nunca foram observados em tal caso. 
ERYTHEMAS ARSENICAES PASSAGEIROS - Foram annotados por CAIN e RAVAUT, em seguida a injecções de salvarsan, estes erythemas passageiros e fugazes. Outros erythemas mais tardios e duradouros foram tambem observados, os quaes, pelo seu aspecto, foram denominados ERYTHEMAS ESCARLATINIFORMES; citam-se tambem casos de manifestações papulosas constituìdas por pequenas papulas vermelhas e rodeadas por uma zona vermelha mais clara: este exanthema foi denominado MORBILLIFORME devido á sua semelhança com o morbillo.

HERPES ZOSTER ARSENICAL - Depois de um tratamento pelo arsenico, nos diz JACOBI, assim como em seguida a um envenenamento pelo oxydo de carbono, pode-se manifestar esta affecção. Vesiculas agrupadas sobre uma base inflammatoria, correspondendo ás terminações cutaneas de um nervo ou de um plexo nervoso.

KERATOSE ARSENICAL - Nesta affecção podemos observar, por exemplo, toda a palma da mão inteiramente recoberta de massas corneas, espessas, hyalinas, cinzentas 012 pardacentas, de permeio com as quaes encontramos varias eminencias corneas dispostas em torno aos conductos excretores das glandulas sudoriparas.

CARCINOMA ARSENICAL - Esse estado de hyperkeratose pode dar origem a carcinomas da pelle como nos dizem LESSER, JACOBI, etc.

PIGMENTACÃO ARSENICAL - A's vezes manifestase sobre o tronco uma pigmentação escura da pelle que é tambem devida ao arsenico. Finalmente é bom notar tambem certos casos de descamação da epiderme como consequencia ao uso do arsenico. 